EXTENDED REPORT

\title{
Haematopoietic malignancies in rheumatoid arthritis: lymphoma risk and characteristics after exposure to tumour necrosis factor antagonists
}

\author{
J Askling, C M Fored, E Baecklund, L Brandt, C Backlin, A Ekbom, C Sundström, \\ L Bertilsson, L Cöster, P Geborek, L T Jacobsson, S Lindblad, J Lysholm, \\ S Rantapää-Dahlqvist, T Saxne, L Klareskog, N Feltelius
}

Ann Rheum Dis 2005;64:1414-1420. doi: 10.1136/ard.2004.033241

See end of article for authors' affiliations

Correspondence to: Dr J Askling, Clinical Epidemiology Unit M9:01, Karolinska University Hospital Solna, SE-171 76 Stockholm, Sweden johan.askling@medks.ki.se

Accepted 6 April 2005

Published Online First 20 April 2005

\begin{abstract}
Background: Patients with rheumatoid arthritis (RA) are at increased risk of malignant lymphomas, and maybe also of leukaemia and multiple myeloma. The effect of tumour necrosis factor (TNF) antagonists on lymphoma risk and characteristics is unclear.

Objective: To assess expected rates and relative risks of haematopoietic malignancies, especially those associated with TNF antagonists, in large population based cohorts of patients with RA.

Methods: A population based cohort study was performed of patients with RA (one prevalent cohort $(n=53$ 067), one incident cohort $(n=3703)$, and one TNF antagonist treated cohort 1999 through 2003 $(n=4160))$, who were linked with the Swedish Cancer Register. Additionally, the lymphoma specimens for the 12 lymphomas occurring in patients with RA exposed to TNF antagonists in Sweden 1999 through 2004 were reviewed.

Results: Study of almost 500 observed haematopoietic malignancies showed that prevalent and incident patients with RA were at increased risk of lymphoma (SIR $=1.9$ and 2.0, respectively) and leukaemia $(S I R=2.1$ and 2.2, respectively) but not of myeloma. Patients with RA treated with TNF antagonists had a tripled lymphoma risk $(S I R=2.9)$ compared with the general population. After adjustment for sex, age, and disease duration, the lymphoma risk after exposure to TNF antagonists was no higher than in the other RA cohorts. Lymphomas associated with TNF antagonists had characteristics similar to those of other RA lymphomas.

Conclusion: Overall, patients with RA are at equally increased risks for lymphomas and leukaemias. Patients with RA treated with TNF antagonists did not have higher lymphoma risks than other patients with RA. Prolonged observation is needed to determine the long term effects of TNF antagonists on lymphoma risk.
\end{abstract}

atients with rheumatoid arthritis (RA) are at increased risk of malignant lymphomas, ${ }^{1-5}$ but the risk determinants and lymphoma characteristics have only begun to be unravelled..$^{6-10}$ For other haematopoietic malignancies in RA, several studies have indicated some degree of increased occurrence of leukaemia, ${ }^{2}{ }^{11-17}$ but the reported risks have varied across strata without a consistent pattern, in part because of insufficient statistical power and diagnostic resolution. It is important to verify increased leukaemia risks , however, as they might reflect yet unestablished side effects of antirheumatic agents. ${ }^{17}{ }^{18}$

With tumour necrosis factor (TNF) antagonists, conspicuously high, and rapid ${ }^{19}$ occurrences of malignant lymphomas have been observed. ${ }^{19-21}$ Although several case reports, case series, ${ }^{1922}$ and crude incidences in series of patients treated with TNF antagonists have been presented, ${ }^{23} 24$ few studies outside a trial setting ${ }^{21}$ have examined the occurrence of malignant lymphomas after TNF antagonist treatment in relation to that among patients with RA not treated with biological agents, or provided characteristics of consecutive lymphomas associated with TNF antagonists in a defined population. Likewise, much of the available data on lymphoma risk in RA reflect cohorts both identified and followed up decades ago, ${ }^{31325}$ and may not apply to contemporary patients. Wolfe and Michaud provide contemporary data based on 29 lymphomas. ${ }^{9}$ They observed a $40 \%$ increased lymphoma risk in patients with RA not treated with TNF antagonists, and a tripled (in comparison with the general population) lymphoma risk in patients receiving treatment with TNF antagonists. ${ }^{9}$

Evidently, before we can evaluate the risk of haematopoietic malignancies in RA, or the level and characteristics of any increased lymphoma risk associated with TNF antagonists, we need contemporary and comparable data on the expected occurrence of haematopoietic malignancies in RA, data on the incidence and risk of lymphomas in patients with RA associated with TNF antagonists, and information on the characteristics of such patients and their lymphomas.

To provide such data on the expected occurrence and risk of haematopoietic malignancies in RA, we followed up one prevalent $(n=53067)$ and one incident $(n=3703)$ cohort of Swedish patients with RA for cancer occurrence during 1990 through 2003 using high quality nationwide health and census registers. To provide data on the risk for malignant lymphomas in patients treated with TNF antagonists, we followed up a cohort of 4160 patients with RA treated with TNF antagonists to determine cancer occurrence in 1999 through 2003 using the same follow up registers (to provide comparability), and compared their lymphoma risk with that

Abbreviations: EBV, Epstein-Barr virus; DAS, Disease Activity Score; $I C D$, International Classification of Diseases; NRN, national registration number; RA, rheumatoid arthritis; SIR, standardised incidence ratio; $\mathrm{TNF}$, tumour necrosis factor 
of the general population, and with that of other patients with RA. Finally, to describe characteristics of lymphomas occurring in anti-TNF treated patients, we present data on all reported lymphomas among patients with RA treated with TNF antagonists in Sweden through 2004.

\section{SUBJECTS AND METHODS Setting}

Swedish health care is public and population based. Hospital referrals are based on geographical determinants rather than financial capacity or health insurance. Nationwide and population based health and census registers in combination with unique personal identifiers allow record linkage of register data recorded prospectively since the 1960s, with very few losses to follow up and minimum risk of recall bias.

\section{The Inpatient Register cohort of prevalent RA}

The Swedish Inpatient Register contains individual based information on inpatient care county wide since 1964 and nation wide since $1987 .{ }^{26}$ For every hospital discharge, information on diagnoses and surgical procedures is recorded according to the International Classification of Diseases (ICD) versions 7-10. We identified all subjects above 16 years of age ever discharged with a diagnosis of RA (primary or contributory diagnosis) between 1 January 1990 and 31 December 2003. The ICD codes used were 714A-C, 714W (ICD 9), and M05-6 (ICD 10). We excluded subjects who were also discharged with systemic lupus erythematosus, ankylosing spondylitis, or psoriatic arthritis. For each patient, computerised information on date of entry (first hospital discharge with RA 1964-2003), discharge department, age, sex, and national registration number (NRN, unique to each resident and recorded in all health and census registers) was recorded (table 1). No information on treatment was available.

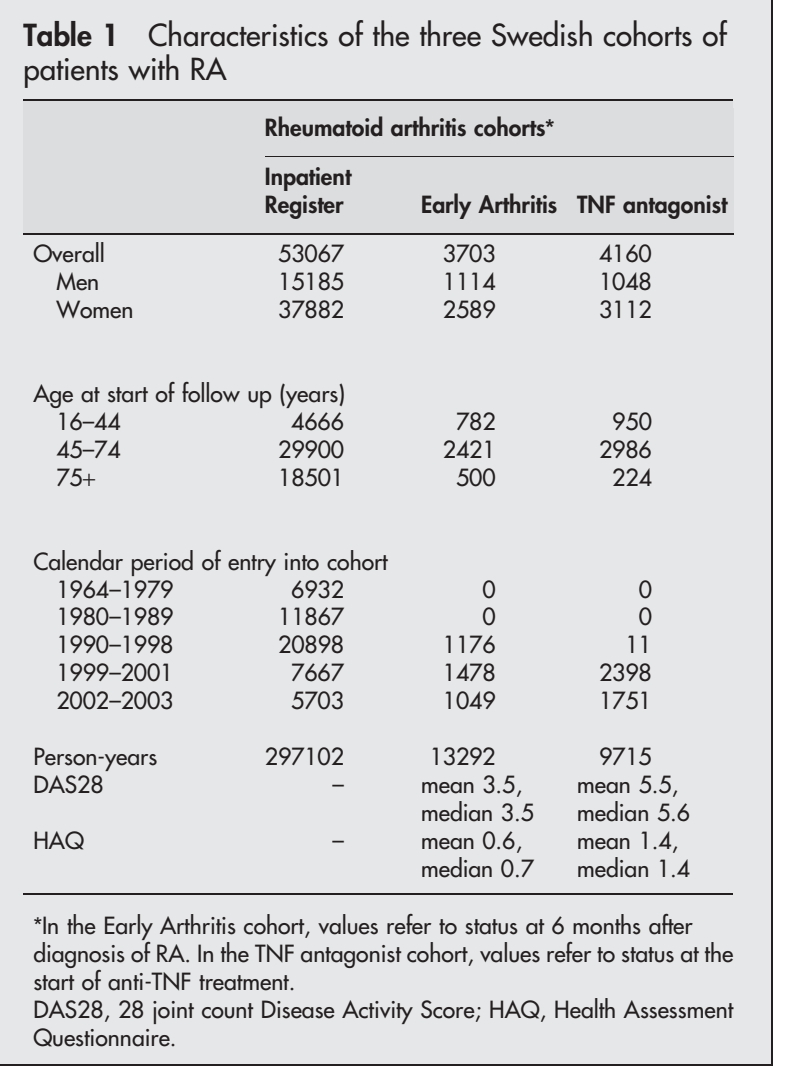

\section{The Early Arthritis cohort of incident RA}

In Sweden, RA is normally diagnosed and followed up by rheumatologists. Centres reporting to the Early Arthritis Register contain a typical mix of small outpatient clinics and larger population based centres. The Early Arthritis Register contains information on subjects with incident $(<1$ year from onset) RA diagnosed at participating centres since the mid-1990s, with a geographically varying but increasing coverage (40-100\% in different regions, overall around $70 \%$ ) of the estimated number of patients with incident RA..$^{27}$ From this register, we collected information on entry (date of diagnosis of RA), date of birth, sex, and the NRN for 3703 incident cases of RA during 1995 through 2003 (table 1).

\section{The TNF antagonist RA cohort}

Within the context of a continuing Swedish structured postmarketing surveillance programme (ARTIS) we assembled a cohort of 4160 patients with RA treated with etanercept, infliximab, or adalimumab between 1999 and 2003 (table 1). Details and patient identification methods have been described elsewhere. ${ }^{28}$ In brief, patients were identified through the Swedish Medical Products Agency in collaboration with the Swedish Society for Rheumatology, and through regional surveillance programmes of patients treated with TNF antagonists. We made assessments against sales statistics, and estimated that our anti-TNF cohort covered around $80 \%$ (higher for etanercept than for infliximab) of all anti-TNF treated patients with RA in Sweden. For each person we collected information on date of birth, sex, NRN, type of TNF inhibitor, Disease Activity Score (DAS)/Health Assessment Questionnaire at the start of treatment, and entry (date of treatment start) and date of discontinuation (table 1).

\section{Register linkages}

Through linkage (of all subjects, using the NRN as linkage key) to the Swedish Cancer Register 1964-2003, we collected information on all registered haematopoietic malignancies (ICD $7=200-209$ ), including the date of diagnosis. Reporting to this registry is mandatory for clinicians and pathologists, resulting in a completeness of around 99\%. ${ }^{29}$ Through linkage to the Cause of Death Register 1964-2003 and to the Register of Population and Population Changes 1969-2003, we collected information on marital status, and vital status, including date of death and date of emigration until 31 December 2003.

\section{Statistics}

In the analyses of relative risk of haematopoietic malignancies, we used SIRs (the ratio of the observed and expected numbers of cancers) as measures of relative risk. Expected numbers were calculated by multiplying sex-, age-, and calendar period-specific person-years of follow up with corresponding rates from the entire Swedish population. Ninety five per cent confidence intervals were calculated assuming a Poisson distribution of the observed cases. In the analyses of SIRs in each cohort, we defined start of follow up as the latest of 1 January 1990 or date of entry into each cohort, and end of follow up as the earliest of date of death, date of emigration, or 31 December 2003. Because some subjects might have entered into the Inpatient Register RA cohort because of an incipient haematological malignancy, we present results both including and excluding the first year after entry into this cohort. We used Poisson regression to model the relative risk of lymphoma in the patients treated with TNF antagonists relative to that in the two other RA cohorts. Because more than $80 \%$ of the total follow up time in the TNF antagonist cohort represented time while receiving treatment, we present relative risks based on the total time of 
Table 2 Relative risk of haematopoietic malignancies including $95 \%$ confidence intervals $(\mathrm{Cl})$ in three Swedish cohorts of patients with RA

\begin{tabular}{|c|c|c|c|c|c|c|}
\hline \multirow[b]{2}{*}{ Type } & \multicolumn{2}{|c|}{ Inpatient Register RA } & \multicolumn{2}{|c|}{ Early Arthritis cohort } & \multicolumn{2}{|c|}{ TNF antagonist cohort } \\
\hline & No & $\operatorname{SIR}(95 \% \mathrm{Cl})$ & No & $\operatorname{SIR}(95 \% \mathrm{Cl})$ & No & $\operatorname{SIR}(95 \% \mathrm{CI})$ \\
\hline All haematopoietic malignancies & 481 & $1.7(1.5$ to 1.8$)$ & 15 & $1.6(0.9$ to 2.6$)$ & 11 & $2.1(1.1$ to 3.8$)$ \\
\hline Malignant lymphoma including CLL & 319 & $1.9(1.7$ to 2.1$)$ & 11 & $2.0(1.0$ to 3.5$)$ & 9 & $2.9(1.3$ to 5.5$)$ \\
\hline Plasma cell neoplasms & 45 & $0.8(0.6$ to 1.1$)$ & 0 & $0.0(0.0$ to 2.2$)$ & 0 & $0.0(0.0$ to 4.2$)$ \\
\hline Leukaemia excluding CLL & 107 & 2.1 (1.7 to 2.5$)$ & 4 & $2.2(0.6$ to 5.7$)$ & 2 & $2.0(0.2$ to 7.3$)$ \\
\hline Acute lymphatic leukaemia & 2 & $0.9(0.1$ to 3.2$)$ & 0 & $0.0(0.0$ to 40.8$)$ & 0 & $0.0(0.0$ to 61.1$)$ \\
\hline Acute myeloid leukaemia & 68 & $2.4(1.9$ to 3.0$)$ & 4 & $4.3(1.2$ to 10.9$)$ & 0 & $0.0(0.0$ to 7.4$)$ \\
\hline Chronic myeloid leukaemia & 13 & $2.4(1.3$ to 4.1$)$ & 0 & $0.0(0.0$ to 17.7$)$ & 0 & $0.0(0.0$ to 27.0$)$ \\
\hline Other or undefined leukaemia & 23 & $1.5(1.0$ to 2.3$)$ & 0 & $0.0(0.0$ to 6.8$)$ & 2 & $6.8(0.8$ to 24.7$)$ \\
\hline Polycytaemia vera & 10 & $0.9(0.4$ to 1.6$)$ & 0 & $0.0(0.0$ to 10.1$)$ & 0 & $0.0(0.0$ to 18.5$)$ \\
\hline
\end{tabular}

Follow up from 1990 (or entry into cohort, if later) until 31 December 2003. Relative risk estimated comparing each cohort with the general Swedish population, adjusting for age, sex, and calendar period.

$\mathrm{CLL}$, chronic lymphocytic leukaemia.

follow up. Sixty nine per cent of the TNF antagonist cohort had been admitted to hospital for their RA, and $27 \%$ of the Early Arthritis cohort had been admitted to hospital for their RA before 31 December 2003. The study was approved by the ethics committee at the Karolinska Institute.

\section{Review of TNF antagonist associated malignant lymphomas 1999-2004}

This case series consisted of all lymphomas identified in the register linkage 1999 through 2003, and all malignant lymphomas reported thereafter (that is, during 2004) as part of rheumatologists' reporting of adverse events within the framework of the ARTIS surveillance programme. To confirm the lymphoma diagnoses, paraffin embedded lymphoma tissues were retrieved from pathology departments, reviewed, and reclassified according to the WHO classification, as previously described. ${ }^{8}$ Epstein-Barr virus (EBV) in the lymphomas was searched for using EBER in situ hybridisation. ${ }^{8}$

\section{RESULTS}

\section{Relative risk of haematopoietic malignancies in the} prevalent RA cohort 1990-2003

Based on 481 observed haematopoietic malignancies occurring in the Inpatient Register RA cohort during 297102 person-years of follow up 1990-2003, the overall relative risk of haematopoietic malignancies was 1.7 (95\% CI 1.5 to 1.8 ; table 2). 319 of these were malignant lymphomas ( SIR $=1.9$, $95 \%$ CI 1.7 to 2.1 ), 107 were leukaemias ( SIR $=2.1,95 \%$ CI 1.7 to 2.5 ), and 45 were multiple myelomas (SIR $=0.8,95 \%$ CI 0.6 to 1.1). Sex- and age-specific incidences of haematopoietic malignancies in this cohort are tabulated in the Appendix.

Apart from the first year after entry, the increased relative risks of malignant lymphoma or leukaemia did not vary with time of follow up (table 3), although a tendency towards increasing relative risks with time was noted for chronic myeloid leukaemia (table 3A). Excluding the first year of follow up from the analyses resulted in an overall SIR of malignant lymphoma $=1.6(95 \%$ CI 1.4 to 1.9$)$.

\section{Relative risk of haematopoietic malignancies in the incident RA cohort 1995-2003}

In the Early Arthritis cohort, the overall relative risks of haematopoietic malignancy ( $\mathrm{SIR}=1.6,95 \%$ CI 0.9 to 2.6 , $\mathrm{n}=15$ ), of malignant lymphomas ( $\mathrm{SIR}=2.0,95 \%$ CI 1.0 to $3.5, \mathrm{n}=11$ ), and of leukaemia ( SIR $=2.2,95 \%$ CI 0.6 to 5.7 , $\mathrm{n}=4$, all myeloid) were of similar magnitude to those of the Inpatient Register RA cohort (table 2). The relative risk of lymphoma did not display any convincing trend $(\mathrm{p}=0.5)$ with increasing duration of RA (table 3B).

\section{Relative risk of haematopoietic malignancies after TNF antagonists 1999-2003}

In the register based follow up 1999-2003, we identified 11 haematopoietic malignancies ( $\mathrm{SIR}=2.1,95 \%$ CI 1.1 to 3.8 ). Nine of these were lymphomas ( $\mathrm{SIR}=2.9,95 \%$ CI 1.3 to 5.6 ) and two were leukaemias ( $\mathrm{SIR}=2.0,95 \%$ CI 0.2 to 7.3 ). The relative risk $(\mathrm{RR})$ for lymphoma did not display any trend with time of follow up (table 3B). When compared with the lymphoma incidence in the prevalent and incident RA cohorts, the adjusted relative risk of lymphoma in the TNF antagonist cohort was 1.1 (95\% CI 0.6 to 2.1 ) (table 4 ). When

Table 3A Relative risk including 95\% confidence intervals (Cls) and observed number of cancers of selected haematopoietic sites by time of follow up in the Swedish Inpatient Register RA cohort 1990-2003. Relative risks comparing the cohort with the Swedish general population, adjusting for age, sex, and calendar period

\begin{tabular}{|c|c|c|c|c|c|c|}
\hline \multirow[b]{2}{*}{ Site (ICD code) } & \multicolumn{6}{|c|}{ No observed, relative risk $(95 \% \mathrm{Cl})$ by time with $\mathrm{RA}^{*}$} \\
\hline & No & $1-4$ years & No & $5-9$ years & No & $10+$ years \\
\hline All haematopoietic malignancies & 129 & $1.5(1.2$ to 1.8$)$ & 98 & $1.5(1.2$ to 1.8$)$ & 154 & 1.5 (1.3 to 1.7$)$ \\
\hline Malignant lymphoma including CLL & 80 & $1.6(1.2$ to 1.9$)$ & 68 & $1.7(1.3$ to 2.2$)$ & 102 & $1.7(1.4$ to 2.0$)$ \\
\hline Plasma cell neoplasms & 14 & $0.9(0.5$ to 1.5$)$ & 7 & $0.6(0.2$ to 1.2$)$ & 13 & $0.7(0.4$ to 1.1$)$ \\
\hline Leukaemia excluding CLL & 30 & $1.9(1.3$ to 2.7$)$ & 21 & $1.7(1.1$ to 2.7$)$ & 38 & $2.0(1.4$ to 2.8$)$ \\
\hline Acute lymphatic leukaemia & 1 & $1.5(0.0$ to 8.2$)$ & 0 & $0.0(0.0$ to 7.1$)$ & 0 & $0.0(0.0$ to 4.5$)$ \\
\hline Acute myeloid leukaemia & 19 & $2.2(1.3$ to 3.5$)$ & 12 & $1.8(0.9$ to 3.2$)$ & 22 & $2.1(1.3$ to 3.2$)$ \\
\hline Chronic myeloid leukaemia & 2 & $1.2(0.1$ to 4.4$)$ & 4 & $3.2(0.9$ to 8.1$)$ & 7 & $3.6(1.5$ to 7.5$)$ \\
\hline Other or undefined leukaemia & 8 & $1.7(0.7$ to 3.4$)$ & 5 & $1.4(0.5$ to 3.3$)$ & 8 & $1.4(0.6$ to 2.8$)$ \\
\hline Polycytaemia vera & 5 & $1.5(0.5$ to 3.5$)$ & 2 & $0.8(0.1$ to 2.8$)$ & 1 & $0.2(0.0$ to 1.3$)$ \\
\hline
\end{tabular}

${ }^{*}$ Counting from date of first discharge listing RA.

$\mathrm{CLL}$, chronic lymphocytic leukaemia. 
Table 3B Relative risk of malignant lymphoma in the Early Arthritis cohort and in the TNF antagonist treated cohort by time since entry into each cohort

\begin{tabular}{lllllll}
\hline & \multicolumn{5}{l}{ No observed, relative risk $(95 \% \mathrm{Cl})$ by years since entry } \\
\cline { 2 - 7 } & No & $<\mathbf{1}$ year & No & $\mathbf{1 - 2}$ years & No & 3+ years \\
\hline Early Arthritis cohort & 2 & $1.5(0.2$ to 5.2$)$ & 4 & $1.8(0.5$ to 4.6$)$ & 5 & $2.4(0.8$ to 5.7$)$ \\
TNF antagonist cohort & 4 & $3.7(1.0$ to 9.4$)$ & 3 & $2.0(0.4$ to 5.8$)$ & 2 & $4.2(0.5$ to 15.3$)$ \\
\hline
\end{tabular}

the first year of follow up in the Inpatient Register RA cohort was excluded, the corresponding relative risk for the TNF antagonist cohort was 1.3 (95\% CI 0.6 to 2.5 ), and when the follow up of the Inpatient Register RA cohort was restricted to the period 1999-2003, the relative risks remained unchanged (data not shown).

\section{Characteristics of TNF antagonist associated lymphomas 1999-2004}

In addition to the nine lymphomas observed in our register based follow up 1999 through 2003, an additional three were reported in the ARTIS programme during 2004. No other lymphomas than those identified in the register linkage had been reported by the rheumatologists during the period 1999 through 2003. The review revealed a distribution of lymphoma subtypes similar to that seen among patients with RA not treated with TNF antagonists, ${ }^{8}$ and a low number $(\mathrm{n}=1)$ of EBV positive lymphomas (table 5).

\section{DISCUSSION}

In this study we present updated information on the expected occurrence of haematopoietic malignancies in patients with RA. With a striking consistency between the cohorts under study, the results indicate that patients with RA are at increased risk not only of malignant lymphomas but also equally of (myeloid) leukaemia. When using these "expected" RA rates as reference we found that patients with RA treated with TNF antagonists were not at any additional increased lymphoma risk compared with patients with RA not treated with TNF antagonists. The case review of TNF antagonist associated lymphomas showed an unremarkable distribution of lymphoma subtypes or EBV positive lymphomas compared with other patients with RA and lymphoma. ${ }^{8}$

The overall level of increase in lymphoma risk associated with RA in our study is in line with previous estimates. ${ }^{1} 2913$ For leukaemia, previous studies have indicated-rather than confirmed-the possibility of increased risks. Because of the low background incidence, reported estimates for leukaemia have been less precise than those for lymphomas, often grouped together in one heterogeneous category including all leukaemia types, for example, ${ }^{3}{ }^{13}$ and have been inconsistent across the sexes, follow up categories, etc. In our study, increased relative risks were seen in all strata of follow up and for men and women. Although we can confirm an increased risk of leukaemia in RA, the extent to which the increased leukaemia risk is caused by the RA itself, its treatment, or both, remains unknown, although the increased risk also in the contemporary and incident RA cohort suggests that historic—or "end stage" — drug regimens in RA like chlorambucil do not in themselves fully explain this increase in risk.

Validation of the RA diagnoses in the Inpatient Register showed that they were diagnostically correct (information available in the medical files versus American College of Rheumatology criteria for $\mathrm{RA}^{30}$ ), close to $90 \%$, with the remainder being made up by other rheumatic diseases or conditions. ${ }^{7}$ Based on reported population prevalences of RA, we estimate that around $50 \%$ of all prevalent cases of RA in Sweden 2003 are covered by the current analyses, which might therefore serve as updated reference rates in current and future safety evaluation of antirheumatic treatments. Despite the presumed qualitative differences between the prevalent Inpatient Register RA cohort and the Early Arthritis

Table 4 Relative risk (RR) including 95\% confidence intervals (CI) of malignant lymphoma in one prevalent cohort, one incident cohort, and one TNF antagonist treated cohort, respectively, of Swedish patients with RA

\begin{tabular}{lrrl}
\hline Covariate & Person-years & Lymphomas ( $\mathbf{n})$ & Relative risk (95\% Cl) \\
\hline RA cohort & 297102 & 319 & 1.0 (reference) \\
Inpatient register cohort & 13292 & 11 & $0.8(0.4$ to 1.4$)$ \\
Cohort with early arthritis & 9715 & 9 & $1.1(0.6$ to 2.1$)$ \\
TNF antagonist cohort & & & \\
Sex & 82596 & 138 & $2.0(1.6$ to 2.4$)$ \\
Male & 237513 & 201 & 1.0 (reference) \\
Female & & & \\
Age at entry (years) & 27702 & 9 & 1.0 (reference) \\
16-44 & 190631 & 197 & $3.1(1.6$ to 6.1$)$ \\
45-74 & 101776 & 133 & $4.1(2.1$ to 8.0$)$ \\
T5+ & & & \\
Time with $R A^{*}$ (years) & 437 & 0 & - \\
Missing & 137053 & 159 & $0.9(0.6$ to 1.1$)$ \\
$0-4$ & 73708 & 73 & $0.8(0.7$ to 1.1$)$ \\
$5-9$ & 108911 & 107 & 1.0 (reference) \\
10+ & &
\end{tabular}

RRs estimated using Poisson regression, adjusted for all parameters in table.

*Counting from date of first discharge with RA (Inpatient Register RA cohort) or specified date of onset of RA (Early Arthritis Register and TNF antagonist cohort). 


\begin{tabular}{|c|c|c|c|c|}
\hline Sex & Year of birth & $\begin{array}{l}\text { Year of } \\
\text { lymphoma }\end{array}$ & Lymphoma subtype & EBV \\
\hline $\mathrm{F}$ & 1918 & 1999 & Unspecified low grade NHL & Neg \\
\hline $\mathrm{F}$ & 1940 & 2000 & Diffuse large B cell lymphoma & $\mathrm{Neg}$ \\
\hline $\mathrm{F}$ & 1926 & 2000 & Follicular lymphoma grade 1 & $\mathrm{Neg}$ \\
\hline M & 1923 & 2000 & Hodgkin, lymphocyłe depletion & Pos \\
\hline $\mathrm{F}$ & 1943 & 2001 & $\begin{array}{l}\text { Follicular lymphoma grade } 3 \\
\text { Diffuse large B cell lymphoma }\end{array}$ & Neg \\
\hline $\mathrm{F}$ & 1954 & 2002 & MALT lymphoma & $\mathrm{Neg}$ \\
\hline M & 1943 & 2002 & Diffuse large B cell lymphoma & NA \\
\hline $\mathrm{F}$ & 1948 & 2002 & Chronic lymphocytic leukaemia & NA \\
\hline M & 1928 & 2003 & Unspecified NHL & NA \\
\hline $\mathrm{F}$ & 1947 & $2004^{*}$ & Unspecified high grade NHL & $\mathrm{Neg}$ \\
\hline $\mathrm{F}$ & 1921 & $2004^{*}$ & Unspecified & Neg \\
\hline $\mathrm{F}$ & 1952 & $2004^{*}$ & Hodgkin, lymphocyłe depletion & Neg \\
\hline
\end{tabular}

incident RA cohort (for example, method of identification, calendar period of entry, duration of RA, and hospitalisation), the relative risks of haematopoietic malignancies were strikingly similar. Although there was an overlap between the cohorts, there was no overlap of haematopoietic malignancies between the Early Arthritis cohort and the TNF antagonist cohort, and the overlap between the TNF antagonist cohort and the Inpatient Register RA cohort did not measurably affect the relative risks observed (data not shown).

Because of the mandatory (for clinicians as well as pathologists) reporting of malignancies to the Swedish Cancer Register, its coverage is near complete. ${ }^{29}$ Previous validations of, for example, 386 lymphomas in Swedish patients with RA 1965-95 showed that $98 \%$ of the registered lymphoma diagnoses were indeed correct, although the register information on lymphoma subtype was limited. ${ }^{7}$ Our register based design thus provided sensitive and valid outcome information, which was ascertained independently of exposure and uniformly in all cohorts. To determine the validity of the lymphoma diagnoses also in this study, and to increase diagnostic resolution further, we retrieved and reanalysed lymphoma specimens from patients in the TNF antagonist RA cohort. In all cases, the lymphoma diagnosis was substantiated by our review.

Data on the relative lymphoma risk associated with TNF antagonists in routine care (that is, beyond the selected patients' phase III trials which suggest an overall fourfold lymphoma risk ${ }^{21}$ ) is scarce, and case series presented by, for example, regulatory agencies are difficult to evaluate because of lack of information on the number of treated patients corresponding with the reported numerator of lymphomas. ${ }^{19}$ In the hitherto largest attempt to assess relative risks outside the trial setting, Wolfe and Michaud followed up patients reported by some 900 rheumatologists to the National Data Bank for Rheumatic Diseases for self reported (but subsequently validated) lymphoma occurrence, and observed 14 lymphomas occurring in TNF antagonist treated patients, and 15 lymphomas in TNF naïve patients. ${ }^{9}$ As in our study, TNF antagonists were associated with a tripled lymphoma risk in comparison with the general population. ${ }^{9}$ In light of the moderate number of observed lymphomas in their study and ours, and the differences in study design, follow up, and outcome ascertainment, the results are remarkably consistent.

In a previous investigation by one of the regional Swedish initiatives to monitor TNF antagonists (SSATG) - which is included in our current report-five lymphomas in patients exposed to TNF antagonists were observed and compared with two lymphomas that occurred in a prevalent comparator RA cohort, which resulted in a relative risk for TNF antagonists compared with other patients with RA of 5.0 (95\% CI 0.9 to 27). ${ }^{31}$ In the pilot Swedish national linkage, the data of which are also included in the current linkage and overlapped with the data reported from the regional initiative, five TNF lymphomas were seen, which corresponded with a doubled relative lymphoma risk (relative risk $=2.2,95 \%$ CI 0.9 to 5.5 ) compared with other patients with RA. ${ }^{32}$

Random variation and increased statistical precision are reasonable explanations for the seemingly divergent results between the two previous and our current Swedish assessment (relative risk compared with other patients with $\mathrm{RA}=1.1,95 \%$ CI 0.6 to $2.1, \mathrm{n}=9$ ). Other tentative explanations include the introduction of TNF antagonists into a prevalent setting of severely ill patients with RA at high risk of lymphoma, but that this degree of selection has attenuated somewhat. Importantly, the apparent difference between the Swedish assessments is unlikely to depend upon differences in the intensity of rheumatologists' reporting of lymphomas as side effects, because all three investigations were based on data reported as part of the mandatory cancer reporting to the Cancer Registry, and no corresponding difference was observed for solid cancers. ${ }^{31} 3334$

Recent data from our group ${ }^{67}$ and others ${ }^{10}$ suggest that the overall almost doubled lymphoma risk in RA has a striking association with the burden of inflammatory activity (but not with antirheumatic treatment). The marginal or lack of increase in lymphoma risk associated with TNF antagonists in our study must therefore be viewed in the context of antiTNF treatment of patients with high disease activity, as indicated by the median DAS28 of 5.6 at the start of anti-TNF treatment, and the more than 10-fold gradient in lymphoma risk between low and high overall burden of inflammatory disease activity among patients with RA. ${ }^{7}$

In the reviewed and reclassified lymphoma series, the distribution of lymphoma subtypes was largely similar to that reported by us in a larger series of lymphomas in Swedish patients with RA not treated with biological agents, ${ }^{8}$ and with that reported by others. ${ }^{35}$ Notably, we found little to suggest an increased proportion of EBV positive lymphomas, which indirectly argues against immune suppression (such as in the immediate post-transplant setting ${ }^{36}$ ) as a critical risk factor. Early reports to MedWatch highlighted the possibility of an immediate increase in lymphoma risk after the start of antiTNF treatment. ${ }^{1921}$ In the study by Wolfe and Michaud no pattern of immediate risk was detected, although infliximab 
Table 6 The observed sex- and age-specific incidence rates (per $100000,95 \%$ confidence interval within parentheses) of haematopoietic malignancies in the Inpatient Register RA cohort 1990-2003

\begin{tabular}{|c|c|c|c|c|c|c|}
\hline \multirow[b]{2}{*}{ Attained age } & \multicolumn{2}{|c|}{ Malignant lymphomas* } & \multicolumn{2}{|c|}{ Multiple Myeloma } & \multicolumn{2}{|l|}{ Leukaemia $^{\star \star}$} \\
\hline & Men & Women & Men & Women & Men & Women \\
\hline $16-19$ & 0 (0 to 5389$)$ & 0 (0 to 2422 ) & 0 (0 to 5389$)$ & 0 (0 to 2422$)$ & 0 (0 to 5389$)$ & 0 (0 to 2422$)$ \\
\hline $20-39$ & $59(6$ to 213$)$ & 18 (2 to 66$)$ & 0 (0 to 137) & 0 (0 to 43$)$ & 0 (0 to 137) & 18 (2 to 66$)$ \\
\hline $40-59$ & 120 (74 to 183$)$ & 60 (41 to 86$)$ & $11(1$ to 41$)$ & $6(1$ to 17$)$ & $29(9$ to 66$)$ & 16 (7 to 31$)$ \\
\hline $60-79$ & 240 (164 to 251$)$ & 93 (76 to 112 ) & 16 (6 to 33$)$ & 16 (10 to 26$)$ & 61 (40 to 89$)$ & 37 (27 to 50$)$ \\
\hline $80+$ & 143 (82 to 232 ) & 116 (86 to 153 ) & 27 (5 to 78 ) & 26 (13 to 47$)$ & 53 (20 to 116$)$ & 38 (22 to 62$)$ \\
\hline
\end{tabular}

treated patients had a seemingly shorter latency between the start of treatment and lymphoma diagnosis. ${ }^{9}$ In our study we found little to suggest an immediate but transient risk increase. Interestingly, however, all four lymphomas that occurred within the first year after starting TNF antagonist treatment occurred in patients with RA who started the treatment in the first half of our study period (1999-2000, data not shown).

In conclusion, patients with RA are at increased risk not only of lymphoma but also of leukaemia. TNF antagonist treatment of RA is associated with, at the most, a marginally augmented lymphoma risk, which still must be judged in the light of a higher disease activity among patients who are offered TNF antagonist treatment. Characteristics of these lymphomas are similar to those seen in patients with longstanding active RA not treated with biological agents. Of necessity, long term lymphoma risk of TNF antagonists, and temporal trends in this risk, remain unknown and warrant prolonged systematic monitoring of large populations treated with TNF antagonists.

\section{ACKNOWLEDGEMENTS}

We gratefully acknowledge the following centres and their Swedish RA register/ARTIS representatives for allowing us to use their data: Yngve Adolfsson, Sunderby Hospital, Luleå; Ewa Berglin, Norrland's University Hospital, Umeå; Torgny Smedby, Östersund County Hospital;Rüdi Götze, Sundsvall County Hospital;Anna-Carin Holmqvist, Hudiksvall's Hospital; Sven Tegmark, Gävle County Hospital; Jörgen Lysholm, Falu lasarett, Falun; Solveig Gustafsson, Karlstad's Central Hospital; Eva Baecklund, Akademiska Hospital, Uppsala; Rolf Oding, Västerås Hospital; Per Salomonsson, University Hospital, Örebro; Birgitta Nordmark, Karolinska University Hospital, Solna; Ingiäld Hafström, Karolinska University Hospital, Huddinge; Göran Lindahl, Danderyd's Hospital, Stockholm; Gun Sandahl, Queen Sophia Hospital, Stockholm; Martin Mousa, Visby lasarett, Visby; Anders Lindblad, Visby Privat, Visby; Åke Thörner, Mälarsjukhuset, Eskilstuna; Lars Cöster, University Hospital, Linköping; Sören Transö, County Hospital Ryhov, Jönköping; Olle Svernell, Västervik's Hospital; Claudia Jacobs, Oskarshamn's Hospital; Bengt Lindell, Kalmar County Hospital; Maria Söderlin, Växjö's CentralHospital; Olof Börjesson, Växjö Privat;Göran Kvist, Centrallasarettet Borås; Karin Svensson, Kärnsjukhuset, Skövde; Tomas Torstenson, Uddevalla Hospital; Ingeli Andreasson, Göteborg privat; Lennart Bertilsson, Sahlgrenska University Hospital, Gothenburg; Tore Saxne, University Hospital in Lund; Miriam Karlsson, Lasarettet Trelleborg; Annika Teleman, Spenshult, Oskarström; Catharina Keller, Helsingborg's Lasarett; Astrid Schröder, Ängelholm's Hospital; Jan Theander, Kristianstad's Central Hospital; Christina Book, MAS University Hospital, Malmö. We thank Maud Rütting, Medical Products Agency, for help with the retrieval of medical files of the lymphoma cases.

Financial support for the Early Arthritis Register was provided by the Swedish National Board of Health and Welfare.

Financial support for this study was obtained from the Swedish Cancer Society, from the insurance company AFA, and from WyethAyerst, Schering-Plough, Abbott Immunology, and Bristol Myers Squibb. The investigators were in charge of, and solely responsible for, all data collection, analysis, and writing of the manuscript, without any constraints exerted by the agencies or companies that helped to sponsor the study.

\section{Authors' affiliations}

J Askling, C M Fored, L Brandt, A Ekbom, Clinical Epidemiology Unit, Department of Medicine, Karolinska University Hospital, Stockholm, Sweden

J Askling, S Lindblad, L Klareskog, N Feltelius, Rheumatology Unit, Department of Medicine, Karolinska University Hospital, Stockholm, Sweden

E Baecklund, Department of Rheumatology, Uppsala University Hospital, Uppsala, Sweden

C Backlin, C Sundström, Department of Genetics and Pathology,

Rudbeck Laboratory, Uppsala University, Uppsala, Sweden

L Bertilsson, Department of Rheumatology, Sahlgrenska University Hospital, Gothenburg, Sweden

L Cöster, Department of Rheumatology, Linköping University Hospital, Sweden

P Geborek, T Saxne, Department of Rheumatology, Lund University Hospital, Lund, Sweden

L T Jacobsson, Department of Rheumatology, Malmö University Hospital, Malmö, Sweden

J Lysholm, Department of Rheumatology, Falu County Hospital, Falun, Sweden

S Rantapää-Dahlqvist, Department of Rheumatology, University Hospital, Umeå, Sweden

N Feltelius, Medical Products Agency, Uppsala, Sweden

\section{APPENDIX}

Table 6 shows the observed sex- and age-specific incidence rates of haematopoietic malignancies in the Inpatient Register RA cohort 1990-2003.

\section{REFERENCES}

1 Ekstrom K, Hjalgrim H, Brandt L, Baecklund E, Klareskog L, Ekbom A, et al. Risk of malignant lymphomas in patients with rheumatoid arthritis and in their first-degree relatives. Arthritis Rheum 2003;48:963-70.

2 Mellemkjaer L, Linet MS, Gridley G, Frisch M, Moller H, Olsen JH. Rheumatoid arthritis and cancer risk. Eur J Cancer 1996;32A:1753-7.

3 Thomas E, Brewster DH, Black RJ, Macfarlane GJ. Risk of malignancy among patients with rheumatic conditions. Int J Cancer 2000;88:497-502.

4 Hakulinen $\mathrm{T}$, Isomaki $\mathrm{H}$, Knekt P. Rheumatoid arthritis and cancer studies based on linking nationwide registries in Finland. Am J Med 1985:78:29-32.

5 Prior P, Symmons DP, Hawkins CF, Scott DL, Brown R. Cancer morbidity in rheumatoid arthritis. Ann Rheum Dis 1984;43:128-31.

6 Baecklund E, Ekbom A, Sparen P, Feltelius N, Klareskog L. Disease activity and risk of lymphoma in patients with rheumatoid arthritis: nested case-control study. BMJ 1998;317:180-1

7 Baecklund E, Ekbom A, Feltelius N, Iliadou A, Backlin C, Askling J, et al. Disease activity, but not DMARD use, increases the risk for malignant lymphoma in rheumatoid arthritis: a case-control study of 378 RA lymphoma patients. Ann Rheum Dis 2004;63(suppl 1):103.

8 Baecklund E, Sundstrom C, Ekbom A, Catrina Al, Biberfeld P, Feltelius N, et al. Lymphoma subtypes in patients with rheumatoid arthritis: increased proportion of diffuse large B cell lymphoma. Arthritis Rheum 2003:48: 1543-50

9 Wolfe F, Michaud K. Lymphoma in rheumatoid arthritis: the effect of methotrexate and anti-tumor necrosis factor therapy in 18,572 patients. Arthritis Rheum 2004;50:1740-51.

10 Wolfe F. Inflammatory activity, but not methotrexate or prednisone use predicts non-Hodgkin's lymphoma in rheumatoid arthritis. Arthritis Rheum 1998;41(suppl 9):188.

11 Bendix G, Bielle A, Holmberg E. Cancer morbidity in rheumatoid arthritis patients treated with Proresid or parenteral gold. Scand J Rheumatol 1995;24:79-84.

12 Gridley G, Klippel JH, Hoover RN, Fraumeni JF. Incidence of cancer among men with the Felty syndrome. Ann Intern Med 1994;120:35-9. 
13 Gridley G, McLaughlin JK, Ekbom A, Klareskog L, Adami HO, Hacker DG, ef al. Incidence of cancer among patients with rheumatoid arthritis. J Natl Cancer Inst 1993;85:307-11

14 Myllykangas-Luosujarvi R, Aho K, Isomaki $\mathrm{H}$. Mortality from cancer in patients with rheumatoid arthritis. Scand J Rheumatol 1995;24:76-8.

15 Cibere J, Sibley J, Haga M. Rheumatoid arthritis and the risk of malignancy. Arthritis Rheum 1997;40:1580-6.

16 Kauppi M, Pukkala E, Isomaki H. Elevated incidence of hematologic malignancies in patients with Sjogren's syndrome compared with patients with rheumatoid arthritis (Finland). Cancer Causes Control 1997;8:201-4.

17 Moder KG, Tefferi A, Cohen MD, Menke DM, Luthra HS. Hematologic malignancies and the use of methotrexate in rheumatoid arthritis: a retrospective study. Am J Med 1995:99:276-81.

18 Danesi R, Del Tacca M. Hematologic toxicity of immunosuppressive treatment. Transplant Proc 2004;36:703-4.

19 Brown SL, Greene MH, Gershon SK, Edwards ET, Braun MM. Tumor necrosis factor antagonist therapy and lymphoma development: twenty-six cases reported to the Food and Drug Administration. Arthritis Rheum 2002:46:3151-8.

20 Bickston SJ, Lichtenstein GR, Arseneau KO, Cohen RB, Cominelli F. The relationship between infliximab treatment and lymphoma in Crohn's disease. Gastroenterology 1999;117:1433-7.

21 Safety update on TNF-alpha antagonists. US Food and Drug Administration Arthritis Drugs Advisory Committee.

22 Liung T, Karlen P, Schmidt D, Hellstrom PM, Lapidus A, Janczewska I, et al. Infliximab in inflammatory bowel disease: clinical outcome in a population based cohort from Stockholm County. Gut 2004;53:849-53.

23 Kavanaugh A, Keenan G, DeWoody K, Masters P, Hendricks D, Clark H, et al. Long-term follow-up patients treated with remicade in clinical trials [abstract]. Arthritis Rheums $2001 ; 44$ (suppl):S81.

24 Barton J, Moreland L, Weinblatt M, Genovese M, White B, Whitmore J, et al. Six years of safety and efficacy of etanercept in rheumatoid arthritis [abstract]. Ann Rheum Dis 2004;63(suppl 1):282.

25 Symmons DP. Neoplasms of the immune system in rheumatoid arthritis. Am J Med 1985;78:22-8.
26 Patientregistret 1987-1996 Kvalitet och innehåll. Stockholm: Epidemiologiskt Centrum, Socialstyrelsen, 1998

27 Soderlin MK, Borjesson O, Kautiainen H, Skogh T, Leirisalo-Repo M. Annual incidence of inflammatory joint diseases in a population based study in southern Sweden. Ann Rheum Dis 2002;61:911-15.

28 Feltelius N, Fored CM, Blomqvist P, Bertilsson L, Geborek P, Jacobsson LT, et al. Results from a nationwide post marketing cohort study of patients in Sweden treated with etanercept. Ann Rheum Dis 2005;64:246-52.

29 Mattsson B, Wallgren A. Completeness of the Swedish Cancer Register. Nonnotified cancer cases recorded on death certificates in 1978. Acta Radiol Oncol 1984;23:305-13.

30 Arnett FC, Edworthy SM, Bloch DA, McShane DJ, Fries JF, Cooper NS, et al. The American Rheumatism Association 1987 revised criteria for the classification of rheumatoid arthritis. Arthritis Rheum 1988;31:315-24.

31 Geborek P, Bladstrom A, Turesson C, Gulfe A, Petersson I, Saxne T, et al. TNF blockers do not increase overall tumour risk in patients with rheumatoid arthritis, but may be associated with increased risk of lymphomas. Ann Rheum Dis 2005;64:699-703.

32 Askling J, Brandt L, Bertilsson L, Fored M, Geborek P, Jacobsson L, et al. Risk for lymphomas following TNF-blockade. Comparisons with a nationwide comorbidity database [abstract]. Ann Rheum Dis 2004;63(suppl I):258.

33 Askling J, Brandt L, Bertilsson L, Feltelius N, Fored M, Geborek P, et al. A National database for comorbidity in RA to evaulate drug-safety. Solid cancers in RA and following anti-TNF treatment [abstract]. Ann Rheum Dis 2004;63(suppl I):85

34 Askling J, Fored CM, Brandt L, Baecklund E, Bertilsson L, Feltelius N, et al. Risks of solid cancers in patients with rheumatoid arthritis and after treatment with tumour necrosis factor antagonists. Ann Rheum Dis 2005;64:1421-6.

35 Kamel OW, Holly EA, van de Riin M, Lele C, Sah A. A population based, case control study of non-Hodgkin's lymphoma in patients with rheumatoid arthritis. J Rheumatol 1999;26:1676-80.

36 Knowles DM. Immunodeficiency-associated lymphoproliferative disorders. Mod Pathol 1999;12:200-17.

\section{bmjupdates+}

bmiupdates+ is a unique and free alerting service, designed to keep you up to date with the medical literature that is truly important to your practice.

bmjupdates+ will alert you to important new research and will provide you with the best new evidence concerning important advances in health care, tailored to your medical interests and time demands.

Where does the information come from?

bmiupdates+ applies an expert critical appraisal filter to over 100 top medical journals A panel of over 2000 physicians find the few 'must read' studies for each area of clinical interest

Sign up to receive your tailored email alerts, searching access and more...

www.bmjupdates.com 